\title{
A Utilização do Design Thinking pelo Designer Instrucional na Produção de Materiais Educacionais Destinados à Educação a Distância
}

\author{
Humberto Costa ${ }^{1 *}$ \\ Tania Stoltz ${ }^{1}$ \\ Trajano Felipe Barrabas Xavier \\ da Silva ${ }^{2}$ \\ ${ }^{1}$ Universidade Federal do Paraná - \\ Setor de Educação \\ Rua General Carneiro, 460 - \\ Centro - Curitiba, PR - Brasil. \\ *humbertoccosta@gmail.com \\ ${ }^{2}$ Universidade do Porto - Faculdade de \\ Engenharia - Rua Dr. Roberto Frias, s/n \\ - Porto - Portugal
}

\section{Resumo}

O objetivo que motivou a realização desta pesquisa foi o de apresentar o método Design Thinking e discutir como sua adoção pode contribuir com o trabalho do designer instrucional que atua no âmbito da Educação a Distância, especialmente na produção de recursos educativos. Partiu-se do princípio de que a adoção do método Design Thinking no contexto da Educação a Distância pode ser tão exitosa, ágil e eficiente tal como se apresenta em outros contextos, como na Educação Presencial, por exemplo. Na discussão, apresenta-se um caso sobre a produção de um recurso audiovisual que terminou em fracasso, mas que poderia ter um resultado diferente, se o método Design Thinking tivesse sido utilizado. Concluiu-se que o Design Thinking tem capacidade para ser utilizado no contexto da Educação a Distância e que profissionais, com diferentes expertises, podem se beneficiar da utilização de tal método, inclusive o designer instrucional. As pesquisas futuras poderiam investigar a aplicação do método Design Thinking na produção de soluções mais complexas, tais como um projeto educacional. Ainda, poderiam investigar a utilização do Design Thinking pelo professor, como auxílio na produção de atividades que visem à colaboração e à experimentação por parte dos alunos.

Palavras-chave: Design thinking. Design instrucional. Educação a distância. Educação. Design.

\section{(c) (i)}

Recebido 29/ 01/ 2020 Aceito 05/ 08/2020 Publicado 06/ 08/ 2020
COMO CITAR ESTE ARTIGO

ABNT: COSTA, H.; STOLTZ, T.; SILVA, T. F. B. X. da. Utilização do Design Thinking pelo Designer Instrucional na Produção de Materiais Educacionais Destinados à Educação a Distância. EaD em Foco, v. 10, n. 2, e953, 2020. DOI: https://doi.org/10.18264/eadf.v10i2.953 


\section{The Use of Design Thinking by the Instructional Designer in the Production of Educational Materials for Distance Education}

\section{Abstract}

The objective that motivated this research was to present the Design Thinking method and discuss how its adoption can contribute to the work of the instructional designer who works in the field of distance education, especially in the production of educational resources. It was assumed that the adoption of the Design Thinking method in the context of distance education can be as successful, agile, and efficient as it is presented in other contexts, such as onsite education, for example. In the discussion, a case is presented about the production of an audiovisual resource that ended in failure, but that could have a different result if the Design Thinking method had been used. It was concluded that Design Thinking has the capacity to be used in the context of distance education and that professionals, with different expertise, can benefit from using such a method, including the instructional designer. Future research could investigate the application of the Design Thinking method in the production of more complex solutions, such as an educational project. Still, they could investigate the use of Design Thinking by the teacher, as an aid in the production of activities aimed at collaboration and experimentation by students.

Keywords: Design thinking. Instructional design. Distance education. Education. Design.

\section{Introdução}

A modalidade de educação a distância (EaD) é, ao mesmo tempo, causa e resultado das mudanças consideráveis na compreensão do significado da palavra Educação, assim como das mudanças no entendimento de como ela deve ser gerida e organizada (MOORE; KEARSLEY, 2010). Tal modalidade educacional experimenta um crescimento considerável no cenário global. No Brasil, segundo o último Censo da Educação Superior, realizado pelo Instituto Nacional de Estudos e Pesquisas Educacionais Anísio Teixeira (INEP), a EaD registrou um crescimento de 17,6\% no período de 2016 a 2017. Os alunos da modalidade EaD são quase 1,8 milhão ou 21,2\% do total de matriculados em todo o Ensino Superior (INEP, 2019). Segundo o Censo EAD.BR, realizado pela Associação Brasileira de Educação a Distância (ABED), mais de 1.500.000 novos alunos se engajaram em cursos a distância no ano de 2018, no Brasil (ABED, 2018, p.60). Embora o crescimento não tenha sido igual ao do período de 2016 para 2017, a ampliação do número de alunos por dois anos consecutivos consolida a modalidade de EaD como opção de formação (ABED, 2019, p.60).

Os desafios contemporâneos demandam novas habilidades e competências por parte da força produtiva, assim como pedem novos produtos ao sistema. Somente a educação presencial não é suficiente para suprir tal demanda (ALVES, 2011). Por suas particularidades, a EaD pode contribuir para atender às demandas educacionais, em especial, naquelas regiões onde as dificuldades de acesso ao ensino são empecilhos consideráveis (CRUZ; SILVA, 2019).

Tanto no âmbito da Educação Presencial (EP), como na EaD, muitos recursos e profissionais estão envolvidos na elaboração de um projeto educacional. Um dos recursos que pode ser utilizado no projeto é o Design Instrucional (DI), aplicado por um designer instrucional (Drl), que é o profissional que orquestra o 
desenvolvimento de um projeto educacional, podendo atuar no âmbito acadêmico e/ou corporativo, em todos os níveis de ensino e nas modalidades de EP e EaD.

O DI surgiu durante a Segunda Guerra Mundial, com o propósito de preparar as forças armadas dos Estados Unidos (MELQUES, 2017). Todavia, o DI só ganhou proeminência nos últimos anos, devido à expansão do uso da tecnologia na educação e com o crescimento da EaD, especialmente no Brasil (KENSKI, 2015).

No desenvolvimento de seus projetos educacionais, o Drl pode utilizar diferentes métodos; um dos que se mostraram ágeis e eficientes em diversas áreas, inclusive no âmbito da EP, é o Design Thinking (DTh). O método DTh utiliza ferramentas oriundas do campo do Design e diz respeito à maneira de pensar empregada no campo do Design. Tal método parte da premissa de que é possível desenvolver um processo intencional para chegar a soluções criativas e inovadoras, capazes de criar impacto positivo e o ser humano ocupa a centralidade desse processo (MARTIN, 2010).

Se o método DTh se mostrou ágil, eficiente e exitoso em diferentes áreas, inclusive no âmbito da EP, como é, então, a sua contribuição para com a EaD? Tal indagação nos conduz ao questionamento: como a aplicação do método DTh pode auxiliar no trabalho do designer instrucional (Drl) que atua na Educação a Distância? ${ }^{1}$ O objetivo que motivou a realização deste estudo foi o de apresentar o método DTh e discutir como sua adoção pode contribuir com melhorias no trabalho do Drl que atua no âmbito da EaD, especialmente na produção de recurso educativo.

A aplicação do DTh no âmbito da EP está amparada por diversas pesquisas (GONSALES, 2014, $\mathrm{KOH}$ et al., 2015; DIEFENTHALER, et al., 2017, LEMKUHLL; PEREIRA, 2017, NOEL; LIUB, 2017 etc.). No entanto, nota-se uma carência de pesquisas acerca da aplicação do DTh no âmbito da EaD. Optou-se por explorar o DTh por diversos motivos, pois trata-se de um método utilizado em diferentes áreas do saber e do fazer humano (NOEL; LIUB, 2017). Este é um tema amplamente pesquisado e utilizado (VIANNA et. al, 2012) para estimular a liberdade e exaltar a colaboração e o trabalho em equipe, além de incentivar engajamento da equipe em diferentes projetos. As soluções geradas atendem ao indivíduo e ao seu contexto; permitem o aprendizado mútuo; fortalecem a confiança criativa (BEDOYA TORO, 2002) e permitem que os resultados de cada etapa do processo possam ser analisados e reflexionados. Ressalta-se que a base na qual o DTh está assentado (empatia, colaboração e experimentação), independe de contexto ou cultura, pois agir de forma empática, ser colaborativo e curioso são qualidades inerentes aos seres humanos (PINHEIRO; ALT, 2011). Outro fator importante é que tanto o método DTh quanto as suas ferramentas podem ser facilmente utilizados por diferentes profissionais. Ao considerar que nem sempre o Drl tem sua formação inicial em Design, a flexibilidade e a versatilidade do DTh e de suas ferramentas, apresenta vantagens qualitativas de se adotar o DTh no desenvolvimento de projetos educacionais.

A partir dessas considerações e para responder ao problema colocado, este artigo versará sobre Educação a Distância, Design Instrucional e Design Thinking, finalizando com a demonstração de como a utilização do DTh poderia contribuir qualitativamente para com o trabalho do Drl, atuante na EaD.

\section{Métodos e técnicas}

A presente pesquisa pode ser caracterizada como de abordagem qualitativa, teórico-empírica, de natureza exploratória e descritiva. Para a sua realização, efetuou-se uma revisão bibliográfica assistemática (GRAY, 2012) e, a partir de um estudo de caso, elaborou-se um roteiro de como o método DTh poderia ser utilizado na produção de um material audiovisual destinado à EaD.

1 Há casos em que o Drl faz todo o trabalho, desde a concepção do curso, até a elaboração dos materiais educacionais a serem utilizados. Também, há casos em que o Drl conta com o apoio de uma equipe em que cada integrante tem sua função bem delimitada (MELQUES, 2017). Em ambas as situações, a adoção do método DTh pode ser de grande valia 
Seguindo as orientações fornecidas por Gray (2012), buscaram-se artigos publicados nas seguintes bases de dados: Periódicos CAPES, Scielo e Science Direct, dissertações e teses circunscritas às áreas pertinentes e presentes nas bases de teses e dissertações da CAPES. Na pesquisa, foram utilizadas as seguintes palavras-chave: Design Thinking, Educação a Distância, Design Instrucional e Designer Instrucional. Apenas os artigos, dissertações e teses publicados entre 2010 e 2019 e revisados por pares foram selecionados. Nessa etapa, 66 materiais foram selecionados. Para refinar o material encontrado, efetuou-se outra seleção com base na leitura dos títulos e resumos (abstract) dos materiais. Os artigos selecionados foram aqueles que apresentaram consonância direta com a temática da pesquisa. Ao final, 14 materiais foram selecionados. Com o propósito de identificar outros materiais que poderiam ser relevantes, o referencial dos materiais selecionados foi consultado, com a finalidade de buscar outros materiais que pudessem contribuir com a presente pesquisa.

Simão Neto (2009, p.161-164) relata o caso de uma editora de livros didáticos que recebeu a tarefa de produzir um material audiovisual que contivesse a versão em áudio da história veiculada por um livro impresso. A nova versão deveria atender a alunos com deficiência visual e deveria servir para aqueles que já usavam o livro impresso. Todavia, o sucesso, do qual o livro impresso gozava, não se repetiu na nova versão, pois o público-alvo preferiu o livro físico. Frente ao fracasso, optou-se pela produção de um novo material, mantendo a configuração de livro impresso com o CD-ROM. A partir desse caso, apresentar-se-á o método DTh como uma solução viável, capaz de reduzir consideravelmente as chances de fracasso de um projeto educacional.

Utilizou-se o caso relatado (Simão Neto, 2009, p.161-164), pois o autor ressalta a importância e a necessidade de se conhecer as especificidades do público-alvo a que um produto se destina. Tal conhecimento visa atender às necessidades específicas que esse público manifesta (LAS CASAS; ALMEIDA; VIANA, 2012; SERCUNDES; LEVAY; FILHO, 2014). Também, o caso permite antever o quão importante é a adoção de um método adequado para guiar um trabalho (produção de materiais). Ainda, ressalta-se que Simão Neto (2009) não aponta a utilização do DTh para solucionar o caso relatado.

\section{Educação a Distância, Design Instrucional e o Design Thinking}

De acordo com o Decreto n. 5.622, de 19 de dezembro de 2005, A EaD caracteriza-se como sendo uma modalidade educacional na qual o processo de ensino-aprendizagem ocorre por meio da utilização de meios e tecnologias de informação e comunicação (TIC), com discentes e docentes desenvolvendo atividades educativas que podem ocorrer de forma síncrona (web conferência, por exemplo) e/ou assíncrona (fórum de discussão, Wiki, etc.). A EaD, tanto em termos de postulados fundamentais quanto em princípios filosóficos, em nada difere da educação presencial quanto à singularidade em que está pautada, especialmente pelo processo de mediação pedagógica, bem como pelo modo no qual os processos de gestão e logística são organizados (SILVA, 2013).

Em dias atuais e no âmbito da EaD, há o uso de recursos como os Massive Open On-line Courses (MOOC) e os Recursos Educacionais Abertos (REA) (RIBEIRO; CATAPAN, 2018). A utilização de tais recursos é possível graças à disponibilidade geográfica da internet, da qualidade das conexões e do uso de dispositivos que permitem que o aprendizado ocorra em praticamente qualquer lugar, tais como os smatphones e os tablets (ALVES, 2011). A construção do conhecimento pode ser facilitada e ampliada por intermédio do alto grau de interação entre aluno, colegas e professores, que, embora se encontrem em espaços diferentes, podem interagir via internet (VALENTE, 2011).

Nesse ínterim, o aluno, ao enfrentar situações conflitantes (por exemplo, em uma web aula ou web conferência), tem a possibilidade de vivenciar os desequilíbrios e os conflitos disponibilizados pelo professor (e/ou pelos colegas) e, se instigado e estimulado, buscará realizar novas adaptações em patamares 
majorantes, tal como pensa Piaget (1976). Ainda, pode-se fazer um paralelo com os estudos de Vygotsky, no que concerne ao conceito de "zona de desenvolvimento proximal" (ZDP) (Cf. VALENTE, 2015). Vygotsky (2002) acredita que a interação entre indivíduos (nesse caso, discentes) com diferentes níveis de conhecimento, oportuniza a ZDP, que é a distância entre o nível de desenvolvimento atual, determinado pela resolução independente de problemas e o nível potencial, determinado pela resolução de problemas sob orientação e/ou colaboração com indivíduos mais capazes (VYGOTSKY, 2002). Por exemplo, o professor pode lançar uma atividade na qual grupos de alunos terão, como tarefa, construir um material informativo sobre determinado assunto. Para registrar a participação dos alunos e acompanhar o desenvolvimento da atividade, o professor pode utilizar um Wiki e colocar-se à disposição para orientações, via um aplicativo de mensagens. O Wiki é uma ferramenta que possibilita aos participantes refletirem, interagirem, colaborarem e cooperarem no processo de construção do conhecimento (PRETTO; PINTO, 2006). As atividades que valorizam a reflexão, a coparticipação, a colaboração e a resolução de problemas favorecem o desenvolvimento da ZDP e dos desequilibrações, tão importantes para a construção do conhecimento.

O termo Design Instrucional assume uma concepção de planejamento, de sequência sistemática de atividades que visam a construir conhecimento e a desenvolver a competência de um indivíduo e, portanto, está sob a égide da aprendizagem (FRANÇA, 2007). Segundo Filatro (2008, p. 37), a “(...) instrução é uma atividade de ensino que se utiliza da comunicação para facilitar a compreensão da verdade." Nessa perspectiva, a instrução não equivale à informação, assim como o DI não equivale ao tratamento e à publicação da informação. O termo instrucional não deve ser entendido como referente à tecnologização do ensino, reforçada pela instrução programada (KENSKI, 2015), pois diz respeito à transformação da informação em conhecimento (REIGELUTH, 1999). Atualmente, entende-se que o DI aplica a lógica e métodos científicos com o propósito de solucionar problemas na concepção e no desenvolvimento de projetos educacionais (BROWN; GREEN, 2016), assim como ao processo pelo qual o conteúdo é apresentado aos discentes, de modo a produzir o maior impacto na aprendizagem (SANDARS; LAFFERTY, 2010).

O conceito de DI refere-se a uma ação intencional e sistemática de ensino com uma abordagem transdisciplinar, envolvendo diferentes áreas do conhecimento. Tal movimento utiliza as TICs para alcançar os objetivos traçados, motivando o desenvolvimento de capacidades e habilidades dos indivíduos que participam das comunidades de aprendizagem, por intermédio de diferentes mídias (ARAUJO; OLIVEIRA NETO, 2010).

Um projeto educacional sob a égide do DI deve envolver uma equipe responsável por desenvolver atividades como levantamento e análise dos seguintes aspectos: necessidades educacionais, perfil dos alunos, concepção e planejamento do projeto educacional, definição de estratégias pedagógicas, conversão ou adaptação dos conteúdos em mídia digital ou outra mídia a ser utilizada, definição de estratégias pedagógicas, colaboração com os autores na programação de estratégias de aprendizagem e avaliações (MOREIRA, 2009).

O Drl é o profissional que orquestra o desenvolvimento de um projeto educacional e pode atuar no âmbito acadêmico e/ou corporativo em todos os níveis de ensino. O Drl tem a função de elaborar o planejamento pedagógico de um curso e de integrar a equipe multidisciplinar na escolha de soluções tecnológicas apropriadas para promover colaboração, cooperação, motivação e significação no aprendizado do aluno (CHAQUIME; FIGUEIREDO, 2013). Suas principais atividades estão relacionadas com os projetos pedagógicos e, portanto, ao “(...) designer instrucional é dada a tarefa de abordar e elaborar estratégias que consolidem uma relação benéfica entre a tecnologia e a educação, com uma aprendizagem colaborativa e autônoma." (BATISTA; MENEZES, 2008, p. 19). Assim, o maior desafio do Drl é o de garantir a qualidade da mediação pedagógica, com ênfase nas necessidades de todos os usuários (RONCARELLI et al. 2010). Isso exige do Drl conhecimentos oriundos de diferentes áreas, tais como Educação, Gestão, Comunicação, Administração, Tecnologia, Engenharia, Design dentre outros, além da atuação interdisciplinar nas diferentes etapas de um projeto educacional (SILVA; DIANA; SPANHOL, 2013). 
A concepção e a implementação de soluções educacionais podem ocorrer em diferentes níveis, e o Drl pode atuar no nível macro, meso ou micro (FILATRO, 2008). No nível macro,

(...) define-se uma direção comum a todas as experiências de aprendizagem de uma instituição, departamento ou programa (expresso, por exemplo, no projeto pedagógico) ou, ainda, se pensarmos nas ações governamentais, definem-se as diretrizes gerais que serão adotadas em âmbito nacional, estadual ou municipal. No nível meso, o design instrucional se ocupa da estruturação de programas, cursos ou disciplinas. Por fim, no nível micro, ele trabalha com o design fino das unidades de estudo (FILATRO, 2008, p. 4).

Segundo a Classificação Brasileira de Ocupações (MTE, 2016), os Drls são profissionais que

(...) implementam, avaliam, coordenam e planejam o desenvolvimento de projetos pedagógicos/instrucionais nas modalidades de ensino presencial e/ou a distância; participam da elaboração, implementação e coordenação de projetos de recuperação de aprendizagem, aplicando metodologias e técnicas para facilitar o processo de ensino e aprendizagem. Atuam em cursos acadêmicos e/ou corporativos em todos os níveis de ensino para atender as necessidades dos alunos, acompanhando e avaliando os processos educacionais. Viabilizam o trabalho coletivo, criando e organizando mecanismos de participação em programas e projetos educacionais, facilitando o processo comunicativo entre a comunidade escolar e as associações a ela vinculadas. Atuam no contexto clínico, avaliando as funções cognitivas, motoras e de interação social dos clientes e promovendo a reabilitação das funções prejudicadas dos mesmos.

Vislumbra-se que o Drl, ao desenvolver um projeto educacional, pode lançar mão do método DTh. Tal método é pouco usual no âmbito da EaD, mas é empregado no âmbito da EP (NOEL; LIUB, 2017). Ressalta-se também que o DTh vem sendo utilizado em outras áreas, como na saúde (MUKAI, 2012) e na gestão de negócios (LOCKWOOD, 2011; FRISENDAL, 2016), por exemplo.

O método DTh utiliza ferramentas do Design e diz respeito à maneira de pensar utilizada no âmbito do Design. Por estar baseado na capacidade humana de intuir, de reconhecer padrões e de desenvolver ideias que tenham um significado racional e emocional (BROW, 2009), pode ser facilmente adotado por diferentes profissionais, em diferentes áreas (MELO; ABELHEIRA, 2015).

Ao abordar um problema pela óptica do DTh, formulam-se questionamentos a partir da compreensão e da apreensão dos fenômenos que estão no contexto do problema; dessa forma, as respostas virão a partir das informações que forem coletadas nesse processo. Percebe-se, então, que a solução não é derivada do problema, mas se encaixa no problema (MELO; ABELHEIRA, 2015), uma vez que se entende que não se pode solucionar adequadamente os problemas com o mesmo tipo de pensamento que os criou.

No cerne do DTh está a busca por equilibrar o raciocínio associativo, o pensamento analítico e o posicionamento das pessoas no centro do processo, com vistas a compreender profundamente as suas necessidades (MELO; ABELHEIRA, 2015). Visando a solucionar os problemas adequadamente, o DTh comunga o que é desejável, do ponto de vista da instituição e das pessoas, com o que é tecnologicamente factível e com o que é economicamente viável (BROWN, 2009). 
O DTh é sustentado por três pilares essenciais que compreendem os problemas, independentemente de sua origem, e lidam com obstáculos, analisam e experimentam novas soluções. São elas: empatia, colaboração e experimentação (BROWN, 2009).

A empatia é o hábito mental que permite pensar nas pessoas como pessoas (BROW, 2009) para tentar compreender seus sentimentos, desejos, sensações, formas de se relacionar, de trabalhar, de agir. A colaboração refere-se à cocriação e deve envolver um grupo heterogêneo de pessoas que oferece diferentes forças e perspectivas, visando a resolver desafios complexos (BROW, 2009). A experimentação diz respeito à necessidade de testar possibilidades e considerar hipóteses, valorizando as tentativas e os erros como partes de qualquer aprendizado (e do processo) (GONSALES, 2018).

Compreender em profundidade o problema das pessoas, projetar soluções viáveis e possíveis, implementar a melhor solução gerada e prototipar tal solução, objetivando testá-la e validá-la junto às pessoas são etapas adotadas no DTh, num processo iterativo e recursivo.

Em 1997, a Organização Mundial da Saúde (OMS) elaborou uma lista chamada "Habilidades para a Vida"; tal lista alcançou amplo reconhecimento, pois é flexível e tem aplicabilidade universal (CASTELLANOS; PINZÓN, 2012). A lista é composta por 10 habilidades: autoconhecimento, empatia, comunicação assertiva, relacionamentos interpessoais, tomada de decisão, resolução de problemas e conflitos, pensamento criativo, pensamento crítico, inteligência emocional e gerenciamento de tensão e estresse (CASTELLANOS; PINZÓN, 2012). No âmbito da Educação, algumas dessas habilidades foram denominadas como "competências socioemocionais". Desde 2015, vêm recebendo atenção da Organização Social para o Desenvolvimento Econômico (OCDE) e de diversas instituições educacionais em todo o mundo, que estão produzindo pesquisas e materiais para apoiar educadores e apoiar a criação de políticas e práticas educacionais relacionadas a essas competências (GONSALES, 2018). Percebe-se que muitas dessas competências socioemocionais estão consonantes com a base do DTh.

Examinando a literatura, pode-se constatar que o DTh está de acordo com os preceitos de pensadores e estudiosos da área da Educação. O Quadro 1 sintetiza tal consonância.

Quadro 1: Pensadores e estudiosos da Educação e a relação com o Design Thinking.

\begin{tabular}{|l|l|l|}
\hline \multicolumn{1}{|c|}{$\begin{array}{c}\text { Pensadores/ } \\
\text { Estudioso }\end{array}$} & \multicolumn{1}{|c|}{ Alguns preceitos } & \multicolumn{1}{c|}{ Relação com o DTh } \\
\hline $\begin{array}{l}\text { John Dewey } \\
(1859-1952)\end{array}$ & $\begin{array}{l}\text { Democratização e igualdade de } \\
\text { portunidades. Aprender com base nas } \\
\text { experiências. Foco na convivência. }\end{array}$ & $\begin{array}{l}\text { O DTh possibilita criar experiências } \\
\text { diversas por intermédio da troca de } \\
\text { ideias, de forma igualitária. }\end{array}$ \\
\hline $\begin{array}{l}\text { Jean Piaget } \\
(1896-1980)\end{array}$ & $\begin{array}{l}\text { O professor como facilitador da } \\
\text { aprendizagem. Trabalho diversificado } \\
\text { por perfil do discente. }\end{array}$ & $\begin{array}{l}\text { O DTh possibilita diversificar as ativida- } \\
\text { des e mediar processos de investigação } \\
\text { e busca de informações. }\end{array}$ \\
\hline $\begin{array}{l}\text { Célestin Freinet } \\
(1896-1966)\end{array}$ & $\begin{array}{l}\text { Cooperação e colaboração entre } \\
\text { discentes e professores. }\end{array}$ & $\begin{array}{l}\text { Todo o processo do DTh se baseia } \\
\text { na interação, colaboração e troca } \\
\text { de ideias. }\end{array}$ \\
\hline $\begin{array}{l}\text { Vygotsky } \\
(1896-1934)\end{array}$ & $\begin{array}{l}\text { Desenvolvimento humano como } \\
\text { resultado da interação com o mundo. } \\
\text { Valorização das experiências vividas. }\end{array}$ & $\begin{array}{l}\text { O DTh tem como base a construção } \\
\text { de protótipos a partir de conhecimentos } \\
\text { prévios. }\end{array}$ \\
\hline $\begin{array}{l}\text { Maria Montessori } \\
(1870-1952)\end{array}$ & $\begin{array}{l}\text { Formação integral do discente. } \\
\text { Educação para a vida. }\end{array}$ & $\begin{array}{l}\text { O DTh coloca a pessoa no centro do } \\
\text { processo. }\end{array}$ \\
\hline $\begin{array}{l}\text { Anísio Teixeira } \\
(1900-1971)\end{array}$ & $\begin{array}{l}\text { Integração escola e sociedade. } \\
\text { Fomentar a autonomia do discente e } \\
\text { prepará-lo para um futuro incerto. }\end{array}$ & $\begin{array}{l}\text { A autonomia é uma tônica do DTh. } \\
\text { Isso estimula a adoção de uma postura } \\
\text { propositiva e proativa, visando à } \\
\text { solução de problemas. }\end{array}$ \\
\hline
\end{tabular}




\begin{tabular}{|l|l|l|}
\hline $\begin{array}{l}\text { Paulo Freire } \\
(1921-1977)\end{array}$ & $\begin{array}{l}\text { Aprender a ler o mundo para poder } \\
\text { transformá-lo. Consciência crítica. } \\
\text { Aprendizagem significativa. }\end{array}$ & $\begin{array}{l}\text { No DTh, os conhecimentos prévios } \\
\text { são fundamentais, assim como os } \\
\text { perfis heterogêneos - o que favorece } \\
\text { a criatividade. }\end{array}$ \\
\hline $\begin{array}{l}\text { Emília Ferrero } \\
(1937-)\end{array}$ & $\begin{array}{l}\text { Processo de aprendizagem deve valori- } \\
\text { zar os erros como etapa fundamental. }\end{array}$ & $\begin{array}{l}\text { O DTh valoriza o erro como elemento } \\
\text { importante no processo. }\end{array}$ \\
\hline
\end{tabular}

É importante ter em mente que o DTh não traz em si uma inovação para a Educação (independente da modalidade), nem mesmo a abordagem pode ser considerada uma inovação se não possibilitar que práticas educativas já consistentes possam continuar sendo feitas ao longo dos tempos, em um processo contínuo (NOEL; LIUB, 2017).

Há alguns modelos de processo do DTh, tais como os propostos por Brow (2009), por Martin (2010) e por Vianna et al. (2012). Um dos mais usados, discutidos e aplicados é o modelo proposto por Brow (2009) e, por tais razões, este será o modelo utilizado nesta pesquisa. Tal modelo é composto por cinco etapas: 1) Empatia (ou imersão), 2) Interpretação, 3) Ideação, 4) Prototipagem e 5) Testes (ver Figura 1).

O trabalho inicia-se na fase da Empatia (ou Imersão). O problema é apresentado à equipe de projeto que se aproxima do contexto do problema, considerando o ponto de vista do cliente e do usuário final (VIANNA et.al., 2012). É comum ocorrer, nessa etapa, uma imersão preliminar e uma imersão em profundidade.

Na imersão preliminar, o profissional reenquadrará o problema e buscará entender o problema inicial, e isto envolve definir o escopo do projeto e identificar os perfis dos usuários e de outros atores-chave que deverão ser envolvidos (Cf. VIANNA et al., 2012). A equipe pode lançar mão de diversas ferramentas nesta fase ${ }^{2}$. Já na imersão em profundidade, a finalidade é a identificação de necessidades e de oportunidades que nortearão a geração de soluções para o problema (Cf. VIANNA et al., 2012). Serão elaborados um plano de pesquisa, protocolos de pesquisa primária, listagem dos perfis de usuários, atores-chave e de interessados (stakeholders) e o mapeamento dos contextos que serão estudados. Ao finalizar as imersões, os dados coletados deverão ser compilados, pois serão fundamentais para a geração de soluções.

A próxima etapa visa à definição real do problema para enquadrá-lo. Para tanto, são necessárias a análise e a síntese das informações que foram coletadas na primeira etapa. Nesta etapa, os dados serão organizados visualmente (ver Figura 4), visando a identificar padrões que auxiliem a compreensão completa do problema. É muito comum que o problema que foi levantado na etapa 1 sofra modificações nesta etapa. $O$ objetivo é ater-se ao real problema que norteará, neste caso, o desenvolvimento da solução a ser entregue.

$\mathrm{Na}$ terceira etapa, a ideação, tem-se por propósito a geração de ideias que estejam alinhadas com o contexto do problema e seleção da ideia que melhor atende às demandas do projeto.

A penúltima etapa é a prototipação. O protótipo é a materialização da ideia, a passagem do abstrato para o físico, de forma a representar a realidade (ainda que de forma simplificada). Um protótipo pode ser de baixa, média ou alta fidelidade. Tudo depende das demandas e do orçamento do projeto. Na etapa de prototipação, as ideias são analisadas e o ciclo pode se repetir até que a equipe de projeto chegue a uma solução final em consonância com as necessidades do projeto. Assim, fica fácil perceber que quanto mais testes e quanto mais cedo se inicia esta etapa, maior o aprendizado e as chances de sucesso da solução final. Essa fase não deve ser negligenciada, pois os protótipos têm a capacidade de minimizar as incertezas do projeto, uma vez que são uma forma ágil de abandonar alternativas que não são bem recebidas e, assim, auxiliam na identificação de uma solução final mais adequada e assertiva.

2 Foge, ao escopo deste trabalho, apresentar e discutir as ferramentas que são utilizadas em um processo de DTh. Para mais informações sobre as ferramentas, sugere-se consultar a obra de VIANNA et al. (2012) e o site Service Design Tools: https:// servicedesigntools.org/tools 
Com a solução final estabelecida, a equipe de projeto irá testá-la junto aos usuários reais para validá-la. O propósito maior é o de ouvir e aprender com os usuários. Portanto, a equipe vai coletar o máximo de informações sobre a solução, estimulando os usuários a fazerem considerações sobre tal solução. Tendo por base avaliação do uso, observações, respostas aos questionamentos colocados pela equipe de projeto e pareceres, será possível perceber o que funcionou ou não funcionou na solução. Ainda há tempo para ajustes, uma vez que o propósito final é o de entregar uma solução adequada ao cliente.

Finalizada a última etapa, a equipe apresentará a melhor solução para o problema que fora colocado. A ideia de entregar algumas soluções e deixar que o cliente escolha aquela que julgar ser a melhor não é adequada, já que cabe ao profissional argumentar e defender sua ideia e provar que ela é a melhor solução para o problema naquele momento.

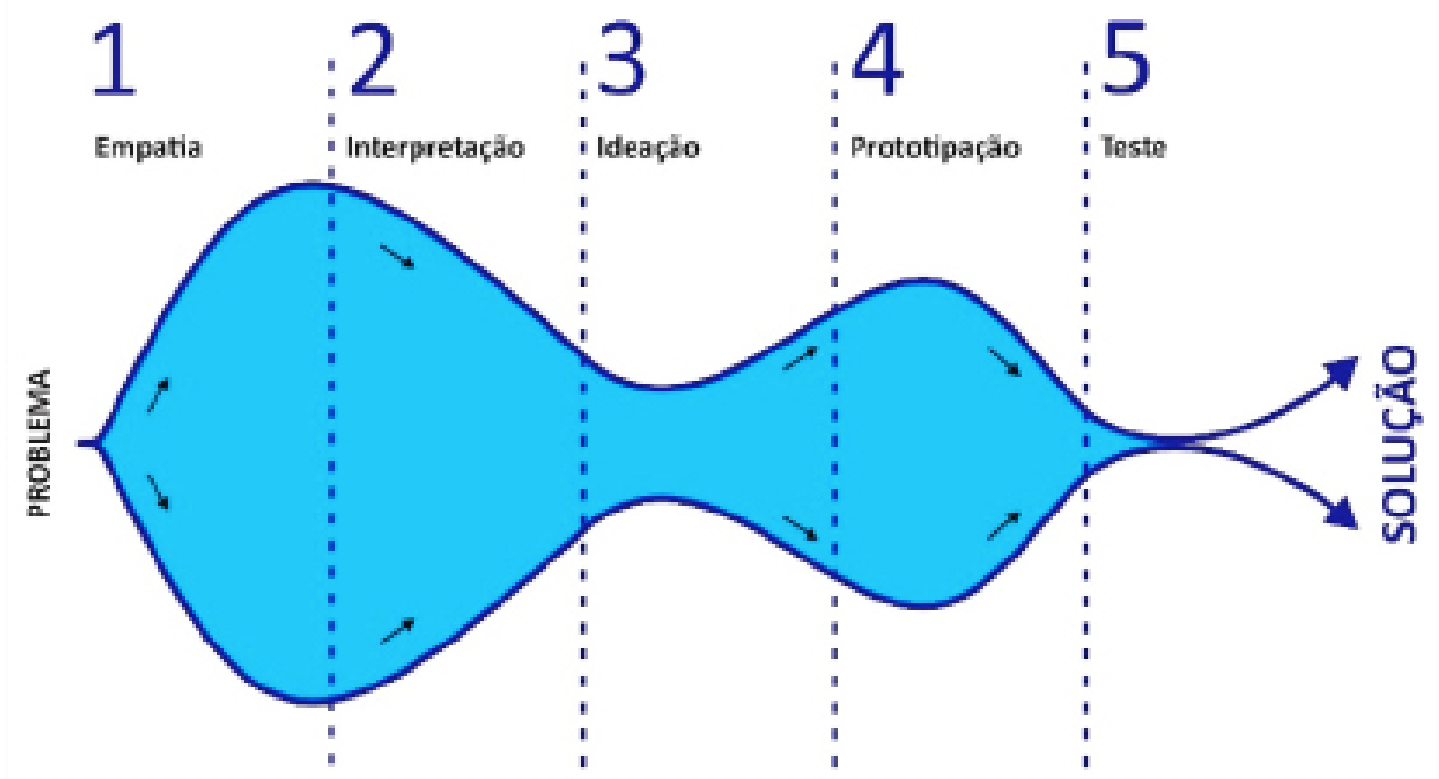

Figura 1: Modelo de processo do Design Thinking.

Fonte: Os autores (2020), com base em Brown (2009).

Em todos os modelos de processo do DTh, o que ressalta é o caráter iterativo e não sequencial das etapas do processo. Isso quer dizer que, se algo der errado em qualquer uma das etapas, pode-se voltar para uma das etapas anteriores, rever o problema e dar continuidade. Por exemplo, tomando o modelo de Brown (2009), se foi detectado um erro na etapa de ideação, pode-se voltar para a etapa de empatia, reexaminar o erro e voltar para a etapa de ideação novamente.

Diferentes mídias podem ser utilizadas no processo educativo graças à evolução das tecnologias de informação e comunicação (TICS), aos inúmeros recursos tecnológicos disponíveis no mercado (smartphones, por exemplo) e ao entendimento de que há diferentes tipos de leitores (SANTAELLA, 2013). A tarefa de educar, quando se toma a educação como construção do conhecimento (JÓFILI, 2002), exige dos atores envolvidos grande desprendimento. Entendendo que a mera transmissão do conhecimento está superada e que a tarefa de se construir o conhecimento é complexa, o planejamento prévio torna-se fundamental. Tal planejamento não envolve somente o professor, mas também os diversos atores que estão envolvidos direta ou indiretamente nesse processo, tais como Drl, professores, tutores, pedagogos, equipe técnica, discentes, pais e a comunidade. 


\section{O caso-problema}

Simão Neto (2009, p.161-162) relata um caso de uma editora de livros didáticos que recebera a tarefa de produzir uma versão audiovisual de um dos seus best sellers educacionais, um livro impresso, destinado ao público adolescente. "Tratava-se de uma obra muito bem escrita, com uma linguagem que agradava em cheio o público a quem se dirigia." O cliente tinha a intenção de que seu best seller impresso também pudesse ser utilizado por alunos com deficiências visuais de moderadas a severas; desta forma , nasceu a ideia de se acrescentar um recurso audiovisual ao livro, na forma de CD-ROM, e tal recurso deveria também servir para aqueles que já usavam o livro impresso.

A editora contratou dois narradores, sendo uma voz feminina e outra masculina. Ambos leram a história que fora gravada em estúdio. Na sequência, o material gravado passou por edição e foram acrescentadas vinhetas, sons incidentais e trilha sonora. O trabalho foi finalizado na forma de CD, sendo este encartado com o livro. O kit foi disponibilizado para venda no mercado (SIMÃO NETO, 2009, p.161-62).

Todavia, o sucesso do qual o livro gozava não se repetiu na versão em áudio, e o resultado do projeto foi negativo. Há o relado de que o público-alvo preferiu o livro físico, “(...) com suas belas ilustrações, seu papel com boa textura e seus textos divididos em pequenas unidades, fáceis de ler." (SIMÃO NETO, 2009, p.162). Ainda, constatou-se que a versão em áudio era ouvida no princípio, mas logo se enjoavam das vozes e do tom utilizado para contar a história. "Assim que percebiam que o CD oferecia exatamente a mesma história do livro, sem nada acrescentar, retirar ou modificar, e que aquelas vozes lendo o texto continuariam pelo CD inteiro, as crianças aposentavam o CD e voltavam ao livro." (SIMÃO NETO, 2009, p.162). Infere-se que se o método DTh tivesse sido adotado, as chances de sucesso do projeto seriam consideravelmente maiores, especialmente pelo fato de que o público-alvo seria consultado e faria parte do processo.

\section{4. Possível solução para o caso-problema apresentado}

O caso relatado por Simão Neto (2009) fornece as diretrizes básicas para projetar o material audiovisual a ser produzido. De acordo com a visão de Filatro (2008), o DI irá atuar no nível micro, uma vez que se tem por tarefa a produção de um recurso educacional.

Como prevê o modelo de processo do DTh proposto por Brow (2009), o trabalho começa pela etapa de empatia, e é neste momento que o Drl vai definir as características básicas do projeto, tais como: equipe de trabalho, estabelecer as tarefas de cada membro da equipe e criar um cronograma do processo. Se o projeto for pequeno, o Drl tem condições de desenvolver a maioria das tarefas da primeira fase, as quais envolvem o mergulho no contexto do problema para compreendê-lo, visando a definir o escopo e os limites do projeto, a identificar os perfis de usuários e de outros atores-chave que deverão ser abordados e a mapear as áreas de interesse a serem exploradas. Nessa fase exploratória, o Drl também vai angariar informações oriundas de outras fontes de dados como, por exemplo, sites, livros, artigos, revistas, blogs, etc., pois há a possibilidade de se identificar tendências acerca da temática ou de assuntos análogos ao problema.

No caso do projeto de elaboração de um recurso audiovisual, a busca por produtos análogos ao CDROM tem capacidade para revelar as tendências e as novidades no âmbito dos materiais audiovisuais. Também é importante que se identifique a existência de produtos similares no mercado, para que se possa fazer uma comparação, identificando pontos negativos e positivos dos materiais, bem como as chances de inovação. Todas as referências encontradas devem ser registradas para uma rápida e fácil consulta ao material levantado, e os achados podem figurar em um quadro visual ou em um portfólio virtual, ancorados em plataformas como Pinterest (https://br.pinterest.com/) ou Canva (https://www. canva.com/), por exemplo. A vantagem de se usar plataformas on-line é a facilidade de acesso ao material em, praticamente, qualquer lugar e a possibilidade de compartilhamento. 
O material coletado anteriormente ajudará no próximo passo, em que deve ocorrer o reenquadramento do problema por diferentes perspectivas e ângulos. O propósito é o de desconstruir crenças e suposições dos atores e afastar-se de padrões de pensamentos circunscritos ao problema do projeto. Ao reenquadrar o problema, há a possibilidade de gerar soluções inovadoras e melhoria de produtos, serviços e/ ou processos. O Drl pode lançar mão da ferramenta brainstorming para obter quantidade de ideias que podem ser combinadas, adaptadas, transformadas e desmembradas em muitas outras ideias. Um brainstorming produtivo é aquele que conta com diferentes pessoas, com diferentes expertises e perspectivas.

O grupo deve envolver representantes do público-alvo do cliente solicitante. É provável que a sessão gere grande número de ideias e, portanto, o passo final será o agrupamento dessas ideias para facilitar a identificação de padrões e chegar a um denominador comum. Há de se estabelecer critérios para a seleção das ideais, e tais critérios podem estar baseados nas três lentes do DTh, por exemplo. Um brainstorming pode ser realizado presencialmente ou pela internet, com a ajuda de plataformas on-line, como o Stormboard (https://stormboard.com/) ou o Miro (https://miro.com/).

Ainda nessa primeira etapa, o Drl vai imergir mais profundamente no contexto do problema, na busca por identificar os anseios, as necessidades e os valores do público-alvo. Também vai inteirar-se acerca das tendências do mercado em que a empresa atua. Nessa fase, técnicas como entrevistas e observação podem ser utilizadas.

É recomendável que o Drl observe como os usuários utilizam, consomem, compram, apropriam-se e significam produtos similares ao que ele está projetando. Primeiramente, o Drl vai selecionar um público similar ao seu público-alvo e vai fazer uma visita de campo. Por exemplo, ir até uma escola, observar como os alunos usam um recurso audiovisual e (havendo possibilidade) entrevistar alguns desses alunos que podem fornecer dados esclarecedores. Talvez haja a oportunidade de observar alguns dos alunos a utilizarem tais produtos em outros contextos, como, por exemplo, em suas casas ou espaços de entretenimento. É fundamental que o Drl registre esses momentos e os achados. O Drl pode lançar mão do uso de cadernos de sensibilização, uma forma de registrar informações sobre pessoas e seus universos, com o mínimo de interferência sobre suas ações. É possível ainda utilizar gravações de áudio e/ou de vídeo como uma forma de registro que pode ser revisitada sempre que necessário. Fazer anotações enquanto se observa ou entrevista alguém não deixam estas de serem atividades interessantes. Enfim, quanto mais o Drl conseguir imergir no contexto do público-alvo, mais proveitosos serão os dados coletados. O resultado dessa etapa será a geração de uma massiva quantidade de dados que serão refinados na etapa seguinte.

A próxima etapa do projeto é a Interpretação. De posse dos dados coletados na etapa de Empatia, o propósito agora é o de se debruçar sobre os dados coletados, visando a identificar o real problema do cliente, comungando com os anseios e as necessidades do público-alvo, tudo de forma clara e passível de soluções inteligentes. É nessa etapa que se define exatamente o público-alvo e ferramentas como Cartões de Insights, Personas e Mapa de Empatia, que são grandes aliadas. Os Cartões de Insights são reflexões embasadas em dados reais, obtidos na primeira etapa. Sempre que se identifica uma questão relevante para o projeto, esta é registrada em um cartão onde deve figurar o achado principal, a fonte e uma explicação sobre o assunto. Personas diz respeito a um personagem fictício, desenvolvido como uma maneira de representar um grupo específico de pessoas. Assim, as personas assumem os atributos dos grupos que representam e revelam vontades e necessidades de pessoas reais. Essa ferramenta auxilia no processo de design porque direciona as soluções para o sentido dos usuários, orienta o olhar sob as informações e apoia as tomadas de decisão sobre o projeto. A ferramenta Mapa de Empatia permite construir um perfil geral acerca do usuário (público-alvo), com base no que ele diz, faz, vê, pensa e consome (VIANNA et al., 2012). Ainda, é possível identificar as fraquezas (ou dores) e as forças (ou necessidades) desse público-alvo. Tal ferramenta é interessante, pois ajudará o Drl a descobrir o universo do público-alvo e, com isso, será possível entender onde tal público enxerga valor. Na internet, há vários modelos que ajudam na elaboração de um Mapa de Empatia (vide: http://canvabrasil.blogspot.com/2012/04/mapa-da-empatia.html). 
Nessa fase, o Drl também pode criar uma lista de critérios norteadores, cujo propósito será o de evidenciar os aspectos que não devem ser perdidos de vista ao longo de todas as etapas do processo. Tais critérios devem servir como base para a determinação do escopo do projeto e do seu verdadeiro propósito.

O resultado dessa etapa é ter uma síntese de dados que demonstrem o problema real do cliente (que pode ser diferente daquele que fora por ele apresentado no início), o perfil detalhado do público-alvo, contendo elementos sobre seus desejos e anseios, além de um panorama acerca do que este público-alvo diz, faz, vê, pensa e consome. Esse resultado será utilizado na etapa seguinte.

A terceira etapa do DTh é a Ideação; é neste momento que o Drl vai interagir com pessoas que têm diferentes expertises. O propósito dessa inclusão é o de comungar diferentes perspectivas e visões de mundo, objetivando tornar o resultado mais rico e assertivo. Essa é a fase de se deixar a criatividade fluir para se obter o maior número de soluções possíveis para o problema. O envolvimento das pessoas com diferentes expertises dar-se-á em sessões de brainstorming e workshop de cocriação. O workshop de cocriação é uma sessão organizada na forma de uma série de atividades em grupo com o propósito de estimular a criatividade e a colaboração, instigando a criação de soluções. Tais sessões devem ser utilizadas quando houver uma quantidade grande de dados que necessitam de um melhor tratamento ou quando for necessário agregar conhecimentos de diferentes especialistas. Usualmente, convidam-se pessoas que estão envolvidas direta ou indiretamente com as soluções que estão sendo projetadas (usuário final e funcionários da empresa demandante do projeto, por exemplo).

Com referência ao caso aqui tratado, o Drl seria o facilitador em um workshop de cocriação e poderia convidar para tal sessão alunos, professores, designers gráficos, designers de experiência e quem mais for julgado interessante para enriquecer o projeto. O Drl vai planejar um roteiro para o workshop e preparar questões específicas que devem ser tratadas pelo grupo. Com base no caso e nos achados, o Drl pode, ainda, propor um workshop de cocriação visando a mapear os principais problemas que ocorrem na utilização de um recurso audiovisual por pessoas com deficiências visuais de moderadas a severas. Outra ideia seria mapear os estímulos necessários para incentivar o público-alvo a usar o livro impresso e o recurso audiovisual que o acompanha.

O resultado da etapa de Ideação é a geração de ideias que possam ser traduzidas na melhor solução para o cliente solicitante, levando em conta a perspectiva do público-alvo. O Drl selecionará aquelas ideias que se mostrarem mais viáveis para a produção e, então, passará para a próxima etapa.

A quarta etapa do DTh é a Prototipação. Tem por objetivo tornar as ideias tangíveis, permitir o aprendizado, enquanto os constrói, dividir tal aprendizado com outras pessoas e auxiliar na validação das ideias que foram geradas. Um protótipo marca a passagem do abstrato para o físico; é a forma de representar a realidade e propiciar validações de modo preliminar. Um protótipo pode ser de baixa (representação conceitual da ideia), média (representação de aspectos da ideia) ou alta fidelidade (representação mais similar possível à solução). Nota-se que, mesmo com um protótipo rústico, é possível conseguir uma resposta direta, além de aprender como melhorar e refinar uma ideia. Com relação ao caso aqui tratado, o Drl pode construir as telas do software que estarão no CD-ROM, objetivando testar a usabilidade desse software junto ao público-alvo.

Quanto mais as ideias forem testadas, maiores serão as chances de sucesso. Protótipos têm a capacidade de reduzir as incertezas do projeto, uma vez que se constituem em uma maneira ágil de abandonar alternativas que não são bem recebidas e, assim, auxiliam na identificação de uma solução mais assertiva.

Embora a etapa de Prototipação seja apresentada como uma das últimas fases do processo de DTh, nada impede o Drl de construir protótipos ao longo do projeto, simultaneamente com a etapa de Empatia e/ou de Ideação. A fase de Prototipação termina com a solução, que será entregue ao cliente solicitante, e será, esta solução, que passará pela última etapa. 
Na última etapa do processo de DTh, a solução gerada (recurso audiovisual) será testada junto ao público-alvo (alunos), quando o Drl avaliará a aceitação da solução junto aos usuários reais. Eis uma oportunidade para coletar dados acerca de possíveis melhorias que poderão ser implementadas em futuras versões do produto.

Se o Drl seguir atentamente todas as etapas do método DTh, é altamente provável que a solução gerada será satisfatória e, com relação ao caso aqui analisado, o erro de ter gerado uma solução enfadonha que cansou os usuários, certamente, não ocorreria. Tampouco se ofereceria aos usuários o mesmo conteúdo do livro impresso. É certo que, se atendidas todas as etapas do DTh, o recurso audiovisual produzido agregaria valor ao livro impresso e estimularia os alunos a quererem usá-los, pois obteriam outros benefícios que foram descobertos durante o processo de produção de tal recurso.

\section{Conclusões}

Esta pesquisa permitiu evidenciar que a utilização do método DTh pelo Drl, no contexto da EaD, pode ser exitosa. Nesse sentido, apresentou o modelo de DTh de Brown (2009), composto por cinco etapas: 1) Empatia (ou Imersão), 2) Interpretação, 3) Ideação, 4) Prototipagem, 5) Testes, e propôs a sua utilização em um caso de fracasso de uma editora de livros didáticos (SIMÃO NETO, 2009). Embora esta pesquisa tenha-se concentrado na utilização do DTh na produção de um recurso audiovisual, percebe-se que tal método pode ser facilmente adaptado para outros desafios, tal como a produção de um projeto educacional inteiro. Ainda, o DTh pode nortear a aplicação de atividades avaliativas em uma disciplina EaD, por exemplo, alunos com um perfil de aprendizado concreto e ativo, que aprendem melhor ao realizar atividades práticas, tais como apresentações, role-plays e debates. Em linhas gerais, a utilização do método DTh é dependente da capacidade criativa do Drl.

Embora o DTh seja muito utilizado e faça parte do contexto de um designer, nada impede que outros profissionais de outras áreas do saber e do fazer humano possam utilizá-lo. Viu-se que a base, na qual o DTh está assentado, independe de contexto ou da cultura para darem certo. Ora, agir de forma empática, ser colaborativo e curioso são habilidades que qualquer pessoa pode desenvolver. Ao considerar que nem sempre o Drl tem sua formação inicial em Design e a flexibilidade e versatilidade do DTh e de suas ferramentas, foi possível perceber que há vantagens qualitativas de conhecer e de adotar o DTh no âmbito da EaD.

Como sugestão para pesquisas futuras, nota-se que há uma premente demanda por pesquisas que demonstrem como o método DTh pode ser adotado na produção de soluções mais complexas, tais como um projeto educacional completo. Ainda, há a demanda de pesquisas que versem acerca de como o DTh pode auxiliar o professor na produção de atividades que visem à colaboração e à experimentação junto a seus alunos.

\section{Financiamento}

Humberto Costa: esta pesquisa contou com o apoio de uma bolsa de pós-doutorado em Educação - CAPES/PRINT: SmartMinds, projeto n.88887.311800/2018-00.

Tania Stoltz: Esta pesquisa contou com o apoio de uma bolsa produtividade em pesquisa do CNPq, processo n.307143/2018-0. 


\section{Agradecimento}

Os autores agradecem à professora Msc. Clarice Alves Martins, pela revisão do texto.

\section{Referências}

ALVES, L. Educação a distância: conceitos e história no Brasil e no mundo. 2011. Disponível em: < http:// www.abed.org.br/revistacientifica/Revista PDF Doc/2011/Artigo 07.pdf>. Acesso em: 03 dez. 2019.

ARAUJO, E.; OLIVEIRA NETO, J. Um novo modelo de design instrucional baseado no ILDF - Integrative Lerning Design Framwork para a aprendizagem on-line. Educação, Formação \& Tecnologias. 2010. Disponível em: <http://eft.educom.pt/index.php/eft/article/view/88>. Acesso em: 06 dez. 2019.

Associação Brasileira de Educação a Distância (ABED). Censo EAD.BR: relatório analítico da aprendizagem a distância no Brasil. Curitiba: InterSaberes, 2019. Disponível em: < http://abed.org.br/arquivos/ CENSO_DIGITAL_EAD_2018_PORTUGUES.pdf>. Acesso em: 10 dez. 2019.

BATISTA, M. L. F. da S.; MENEZES, M. dos S. O design gráfico e o design instrucional na Educação a Distância. Disponível em: <http://portal.anhembi.br/sbds/pdf/7.pdf>. Acesso em: 12 dez. 2019.

BEDOYA TORO, M.E. La Formación de la competencia Investigativa en los estudiantes del Instituto Tecnológico Metropolitano. 2002. Disponível em: <http://ayura.udea.edu.c0:8080/jspui/ handle/123456789/296>. Acesso em: 12 dez. 2019.

BROWN, A. H.; GREEN, T. D. The essentials of instructional design: connecting fundamental principles with process and practice. 3.ed. New York: Routledge, 2016.

BROWN, T. Design Thinking: Uma metodologia poderosa para decretar o fim das velhas ideias. Rio de Janeiro: Alta Books, 2009.

CASTELLANOS, L. M., PINZÓN, I. D. C. Habilidades para la vida. 8.ed. Bilbao: EDEX, 2012. Disponível em: <http://habilidadesparalavida.net/eBook/\#p=2>. Acesso em: 05 dez. 2019.

CHAQUIME, L. P.; FIGUEIREDO, A. P. S. O papel do designer instrucional na elaboração de cursos de educação a distância: exercitando conhecimentos e relatando a experiência. 2013. Disponível em: <http://www.aedi.ufpa.br/esud/trabalhos/poster/AT2/114065.pdf>. Acesso em: 03 dez. 2019.

CHIAVANETO, I.; SAPIRO, A. Planejamento Estratégico. São Paulo: Elsevier, 2010.

CRUZ, J. R.; LIMA, D. da C. P. Trajetória da educação a distância no Brasil: políticas, programas e ações nos últimos 40 anos. 2019. Disponível em: <https://revistas.ufpr.br/jpe/article/view/64564>. Acesso em: 04 dez. 2019.

DIEFENTHALER, A. et al. Thinking \& Acting like a Designer: How design thinking supports innovation in K-12 education. 2017. Disponível em: <https://designthinking.ideo.com/resources/thinking-acting-likea-designer-how-design-thinking-supports-innovation-in-k-12-education>. Acesso em: 05 dez. 2019.

FILATRO, A. Design Instrucional na prática. São Paulo: Pearson, 2008.

FRANÇA, G. O Design Instrucional na Educação a Distância. São Paulo: Esfera, 2007.

FORMIGA, M. (Orgs.). Educação a Distância: o estado da arte. São Paulo: Pearson Education do Brasil, 2009.

FRISENDAL, T. Design thinking business analysis: business concept mapping applied. Kingston: Springer, 2016. 
GONSALES, P. Design Thinking e a ritualização de boas práticas educativas. São Paulo: Instituto Educadigital, 2018.

Instituto Nacional de Estudos e Pesquisas Educacionais Anísio Teixeira - INEP. Resumo técnico do Censo da Educação Superior 2017. Brasília: Instituto Nacional de Estudos e Pesquisas Educacionais Anísio Teixeira, 2019. Disponível em: <http://download.inep.gov.br/educacao superior/censo superior/ resumo tecnico/resumo tecnico censo da educacao superior 2017.pdf>. Acesso em: 10 dez. 2019.

JÓFILI, Z. Piaget, Vygotsky, Freire e a construção do conhecimento na escola. 2002. Disponível em: <https://www.maxwell.vrac.puc-rio.br/7560/7560.PDF>. Acesso em: 23 out. 2019.

KENSKI, V. M. Design Instrucional para cursos on-line. São Paulo: Senac, 2015.

$\mathrm{KOH}$, J. H. L. et al. Design thinking for education: Conceptions and applications in teaching and learning. Singapore: Springer, 2015.

LAS CASAS, A. L.; ALMEIDA, K. P. dos R. de; VIANA, R. B. de C. Identificando o perfil do público-alvo dos cursos de graduação na modalidade de educação a distância, no brasil: uma análise exploratória. 2012. Disponível em: <http://www.revistarebram.com/index.php/revistauniara/article/view/74/53>. Acesso em: 07 jun. 2020.

LOCKWOOD, T. Design thinking: integrating innovation, customer experience, and brand value. New York: Design Management Institute, 2009.

MARTIN, R. Design de Negócios. São Paulo: Elsevier, 2010.

MELO, A.; ABELHEIRA, R. Design Thinking \& Thinking... Design. São Paulo: Novatec, 2015.

MELQUES, P. M. Designer educacional: conceituação a partir das abordagens de educação CCS e EJV no contexto de cursos na modalidade a distância. 2017. 208f. Tese (doutorado em Educação) Universidade Estadual Paulista, Presidente Prudente, 2017.

MOREIRA, M. G. A composição e o funcionamento da equipe de produção. In: LITTO, F. M.; FORMIGA, M. (Orgs.). Educação a distância: o estado da arte. São Paulo: Pearson Education do Brasil, 2009, p. $370-378$.

MOORE, M.; KEARSLEY, G. Educação a distância: uma visão integrada. São Paulo: Cengage Learning, 2010.

MUKAl, H. Sistemas Integrados de gestão de design, qualidade, ambiente, saúde e segurança no trabalho: aplicação às pequenas e médias empresas do setor moveleiro. Tese (Doutorado em Engenharia de Produção) - Universidade Federal de Santa Catarina, SC, 2012.

NOEL, L.; LIUB, T. L. Using Design Thinking to Create a New Education Paradigm for Elementary Level Children for Higher Student Engagement and Success. 2017. Disponível em: <https://ojs.lboro. ac.uk/DATE/article/view/2198>. Acesso em: 08 dez. 2019.

PIAGET, J. A Equilibração das Estruturas Cognitivas. Rio de Janeiro: Zahar, 1976.

PINHEIRO, T.; ALT, L. Design Thinking Brasil. Rio de Janeiro: Campus, 2011.

PRETTO, N.; PINTO, C. da C. Tecnologias e Novas Educações. Revista Brasileira de Educação. Bahia: vol. 11 n.31, jan./abr. 2006.

REIGELUTH, C. Instructional-design theory and models: a new paradigm of Instructional Theory. v. II. Lawrence Erlbaum Associates, 1999. 
RIBEIRO, L. O. M.; CATAPAN, A. H. Plataformas MOOC e Redes de cooperação na EaD. 2018. Disponível em: <https://www.aunirede.org.br/revista/index.php/emrede/article/view/297>. Acesso em: 08 jun.2020.

RONCARELLI, D. et al. Desafios e perspectivas do design instrucional: contexto sociotécnico, saberes e abordagens pedagógicas. In: II Seminário Nacional em Estudos da Linguagem: Diversidade, Ensino e Linguagem, Cascavel-PR. 2010.

SANDARS, J.; LAFFERTY, N. Twelve tips on usability testing to develop effective e-learning in medical education. 2010. Disponível em: <https://www.tandfonline.com/doi/abs/10.3109/0142159X 2010.507709?.journalCode=imte20>. Acesso em: 17 dez. 2019.

SANTAELLA, L. Desafios da ubiquidade para a educação. 2013. Disponível em: <https://www. revistaensinosuperior.gr.unicamp.br/artigos/desafios-da-ubiquidade-para-a-educacao>. Acesso em: 22 out. 2019.

SERCUNDES, J. S.; LEVAY, P. B.; FILHO, R. A. de M. O contexto do público-alvo como base para o planejamento de materiais didáticos e aulas na educação a distância. 2014. Disponível em: <https://repositorio.ufsc.br/xmlui/bitstream/handle/123456789/132003/2014-311. pdf?sequence=1 \&isAllowed=y>. Acesso em: 07 jun. 2020.

SILVA, A. R. L. da; DIANA, J. B.; SPANHOL, F. J. Designer instrucional: da formação múltipla a atuação interdisciplinar. 2013. Disponível em: <http://www.labmidiaeconhecimento.ufsc.br/files/2014/11/ desgner.pdf>. Acesso em: 11 dez. 2019.

SIMÃO NETO, A. Didática e design instrucional. Curitiba: IESDE, 2009. 312 p.

VALENTE, J. A. Educação a distância: criando abordagens educacionais que possibilitam a construção de conhecimento. In: ARANTES, V. A. (Org.). Educação a distância. São Paulo: Summus, 2011.

VIANNA, M. et al. Design Thinking: inovação em negócios. Rio de Janeiro: MJV Press, 2012.

VYGOTSKY, L. S. A formação social da mente: o desenvolvimento dos processos psicológicos superiores. São Paulo: Martins Fontes, 2002. 